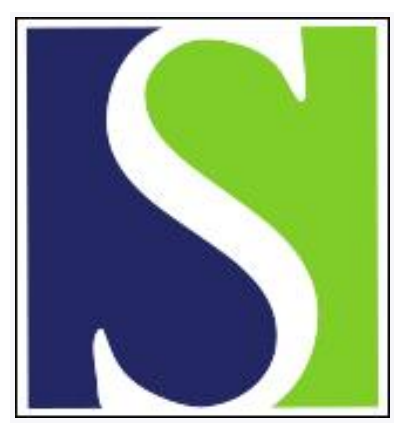

Scand J Work Environ Health 1983;9(6):497-503

https://doi.org/10.5271/sjweh.2383

Issue date: Dec 1983

Monitoring 1,6-hexamethylene diisocyanate in air by chemosorption sampling.

by Andersson K, Gudehn A, Hallgren C, Levin JO, Nilsson CA

This article in PubMed: www.ncbi.nlm.nih.gov/pubmed/6673107

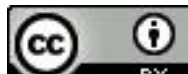




\title{
Monitoring 1,6-hexamethylene diisocyanate in air by chemosorption sampling
}

\author{
by Kurt Andersson, PhD, ${ }^{1}$ Ann Gudéhn, BSc, ${ }^{2}$ Christer Hallgren, BSc, ${ }^{1}$ \\ Jan-Olof Levin, $\mathrm{PhD},{ }^{1}$ Carl-Axel Nilsson, $\mathrm{PhD}^{1}$
}

\begin{abstract}
ANDERSSON K, GUDEHN A, HALLGREN C, LEVIN J-O, NILSSON C-A. Monitoring 1,6-hexamethylene diisocyanate in air by chemosorption sampling. Scand $j$ work environ health 9 (1983) 497-503. A sampling procedure for 1,6-hexamethylene diisocynate (HDI) in air is described. The diisocyanate is trapped on a chemosorption tube containing 9-(N-methylaminomethyl)anthracene adsorbed on Amberlite XAD-2. Recoveries in the laboratory experiments were $81-91 \%$. The chemosorption technique was evaluated in the field by measurements at two different factories using HDI as a hardener in twocomponent paints for vehicle refinishing. Simultaneous sampling with a fritted-glass bubbler and by the chemosorption technique showed equal collection efficiencies for HDI when 3.5- to 22-1 air samples were used. For air samples exceeding 201 the collection efficiency of the fritted-glass bubbler decreased. Several additional peaks appeared in the chromatograms from the fritted-glass bubblers. Statistical treatment of the data showed that these peaks are closely related to the amount of HDI.
\end{abstract}

Key terms: airborne isocyanates, 4,4' -diphenylmethane diisocyanate, isocyanate, toluene diisocyanate.

Aromatic and aliphatic diisocyanates have found widespread industrial use in the production of polyurethane materials, such as flexible and rigid foams, adhesives, elastomers, paints, and coatings. 1,6-Hexamethylene diisocyanate (HDI) is added to two-component paints used, eg, in the vehicle refinishing industry. Methods for analyzing and sampling diisocyanates, which may be toxic when inhaled $(13,14)$, are required.

A spectrophotometric method for determining aliphatic diisocyanates in air was introduced by von Eicken (5) and later modified $(16,20)$. The diisocyanates are hydrolyzed to the corresponding amines and then coupled with 1-fluoro-2,4-dinitrobenzene to form a colored derivative. Aromatic and aliphatic diisocyanates, their related oligomers, and the corresponding

1 National Board of Occupational Safety and Health, Department of Occupational Health in Umeå, S-900 06 Umeá, Sweden.

2 Department of Organic Chemistry, University of Umeå, S-901 87 Umeå, Sweden.

Reprint requests to: Ms A Gudéhn, Department of Organic Chemistry, University of Umeå, S-901 87 Umeå, Sweden. amines all respond quantitatively to this method. Esposito \& Dolzine (6) developed a gas-liquid chromatographic method for the determination of HDI in air. HDI was collected as the amine analogue and then derivatized with heptafluorobutyric anhydride and subsequently analyzed by gas liquid chromatography using electron capture detection.

Several methods using one-step derivatization with subsequent chromatographic analyses have been introduced for the determination of both aromatic and aliphatic diisocyanates. These compounds can now be selectively analyzed at low levels. The reagents used are N-p-nitrobenzyl-N- $n$ propylamine $(4,8,9,17)$, 1-naphthalenemethylamine (11), 9-(N-methylaminomethyl)anthracene (18), N-methyl-1-naphthalene methylamine (10), 1-(2-methoxyphenyl)piperazine (21), and 1-(2-pyridyl)piperazine (7).

The sampling of diisocyanates in workroom air has received less attention however, and, with a few exceptions $(3,15,19)$, these methods suffer from the drawback of using liquid absorber samplers. We recently developed a sampling method using 
chemosorption (1), in which the diisocyanates are trapped on Amberlite XAD-2 coated with $1 \% 9$-(N-methylaminomethyl) anthracene (MAMA). The derivatives are desorbed with $\mathrm{N}, \mathrm{N}$-dimethylformamide and subsequently analyzed by high-performance liquid chromatography (HPLC). Chemosorption sampling has been evaluated in the field for toluene diisocyanate (1) and for 4,4-diphenylmethane diisocyanate (2). The purpose of this study was to evaluate the chemosorption sampling method for HDI.

\section{Materials and methods}

\section{Chemicals}

Acetonitrile (Rathburn Chemicals, HPLC grade), toluene (May \& Baker, analytical purity), triethylamine (Merck), N,N-dimethylformamide (Mallinckrodt, analytical purity), and HDI (Fluka, puriss) were used without further purification. Water was purified in a Millipore Milli $R / Q$ water purifier. 9-(N-methylaminomethyl)anthracene hydrochloride (MAMA $\cdot \mathrm{HCl}$ ) was purchased from Sangö \& Zimerson (18).

\section{Reagent solution}

One hundred and twenty-five milligrams of MAMA $\cdot \mathrm{HCl}$ was dissolved in $25 \mathrm{ml}$ of 0.1-mol/1 hydrochloride. The aqueous phase was washed twice with $12.5 \mathrm{ml}$ of toluene. The toluene phases were discarded. The free amine was precipitated by the addition of $25 \mathrm{ml}$ of $1-\mathrm{mol} / 1$ sodium hydroxide. The amine was extracted with two 15-ml portions of toluene, and the volume adjusted to $100 \mathrm{ml}$ with toluene (reagent solution A). Twenty milliliters of reagent solution A was further diluted with toluene to contain a MAMA concentration of $10^{-4} \mathrm{~mol} / \mathrm{l}$.

\section{Adsorbent}

Amberlite XAD-2 (Rohm \& Haas) is a cross-linked styrene divinylbenzene copolymer. For the elimination of salts and fines, the polymer was washed and decanted in water seven times, in methanol (puriss) five times, and in methanol (analytical purity) twice. The polymer was frac- tioned and the beads between 20 and 50 mesh were collected. These were then Soxhlet-extracted twice for $12 \mathrm{~h}$ in diethyl ether (analytical purity) and finally dried overnight at $60^{\circ} \mathrm{C}$.

\section{Chemosorption tubes}

Eighty milliliters of reagent solution A was added to $10 \mathrm{~g}$ of purified XAD-2. The toluene was evaporated in a rotary evaporator at $50^{\circ} \mathrm{C}$. The chemosorbent $(150 \mathrm{mg})$ was filled in a $6-\times-50-\mathrm{mm}$ glass tube (inner diameter $4 \mathrm{~mm}$ ) similar to an ordinary charcoal sampling tube. The tubes were stoppered at both ends with silanized glass wool.

\section{Standard solutions}

HDI was diluted in toluene to give 525, 105 , and $10.5 \mu \mathrm{g} / \mathrm{ml}$. The urea-derivative standard solutions were prepared by the addition of $10 \mu \mathrm{l}$ of the HDI standard solutions to $10 \mathrm{ml}$ of MAMA (10. $\left.{ }^{4} \mathrm{~mol} / \mathrm{l}\right)$ in toluene. The toluene was evaporated, and the residue dissolved in $2 \mathrm{ml}$ of $\mathrm{N}, \mathrm{N}$-dimethylformamide.

\section{Recovery studies}

Ten microliters of the HDI standard solution was injected into a preheated $\left(40^{\circ} \mathrm{C}\right)$ glass tube connected to the chemosorption tube; $15 \mathrm{l}$ of air was pumped through the tube at a flow rate of $11 / \mathrm{min}$.

\section{Field measurements}

Each experimental setup included one fritted-glass bubbler with $10 \mathrm{ml}$ of MAMA $\left(10^{-4} \mathrm{~mol} / \mathrm{l}\right)$ in toluene and one chemosorption tube in parallel. The chemosorption tubes were backed up by a fritted-glass bubbler containing $10 \mathrm{ml}$ of MAMA $\left(10^{-4}\right.$ $\mathrm{mol} / \mathrm{l}$ ) in toluene. Measurements were performed at two different factories (A and $\mathrm{B}$ ) using HDI as a hardener in two-component paints for vehicle coating. Short periods $(2-5 \mathrm{~min})$ of spraying were generally required to repair damage to the body coating. The total sampling time varied between 3 and $60 \mathrm{~min}$, and each sample included one to three periods of paint spraying. Sampling was performed in the ventilated spray-box in which the vehicles were sprayed. The paint used in factory A was Lesonal, the temperature was $20-22^{\circ} \mathrm{C}$, 
and the relative humidity $40-44 \%$. Factory $B$ used Glassodur and Lesonal paints. The temperature was $22-24^{\circ} \mathrm{C}$, and the relative humidity $38 \%$.

\section{Analysis}

The toluene in the fritted-glass bubbler reagent solutions was allowed to evaporate overnight in a hood, and the residue was dissolved in $2 \mathrm{ml}$ of $\mathrm{N}, \mathrm{N}$-dimethylformamide. The chemosorption tubes were desorbed by the shaking of the chemosorbent with $2 \mathrm{ml}$ of $\mathrm{N}, \mathrm{N}$-dimethylformamide for $30 \mathrm{~min}$. The solutions were filtered through a Millex R -SR $(0.5 \mu \mathrm{m})$ filter prior to the analysis. The chromatographic runs were performed with a Waters HPLC instrument, consisting of a WISP 710 A autosampler, a M6000 A solvent deliver system, a M440 ultravioletabsorbance detector, and a data module. The instrument was further equipped with a Waters radial compression separation system with a $\mathrm{C}-18$ reversed phase column $(8 \times 100 \mathrm{~mm}, 5 \mu \mathrm{m})$ operating at a flow rate of $1.5 \mathrm{ml} / \mathrm{min}$ [pressure approximately 600 pounds per square inch $\left.\left(4,137 \cdot 10^{4} \quad \mathrm{~Pa}\right)\right]$. The chromatographic eluent consisted of $200 \mathrm{ml}$ of water, containing $2.5 \%$ triethylamine, with the $\mathrm{pH}$ adjusted to 3.0 with concentrated phosphoric acid. The water was diluted to 1.01 with acetonitrile. The detector was operated at $254 \mathrm{~nm}$, and $15 \mu \mathrm{l}$ was injected. The minimum detectable quantity was $0.5 \mathrm{ng}$. Recoveries were determined with the use of the external standard method.

\section{Data analysis}

The chromatograms were analyzed by the PLS (partial least squares in latent variables) generalized pattern recognition method $(12,22)$. With this method one set of "dependent" variables $(\mathrm{Y})$ can be related to another set of "independent" variables (X) measured on the same set of samples ( 1 to $\mathrm{n}$ ). The PLS method simultaneously derives (i) a model which approximates the variation in the $X$ variables in a way similar to factor and principal component analysis, and (ii) a relationship between $\mathrm{Y}$ and $\mathrm{X}$. The former is described by the PLS scores $t$.

The HDI derivative peak (p1) and three additional peaks $(\mathrm{p} 2-\mathrm{p} 4)$ were selected from the HPLC chromatogram (fig 1), and the peak heights were measured. Information from the $\mathrm{p} 2-\mathrm{p} 4$ peaks was related to the amount of free monomeric HDI derivative.

\section{Results and discussion}

\section{Recovery experiments}

As can be seen from table 1 , all the recoveries were high. The tubes with the

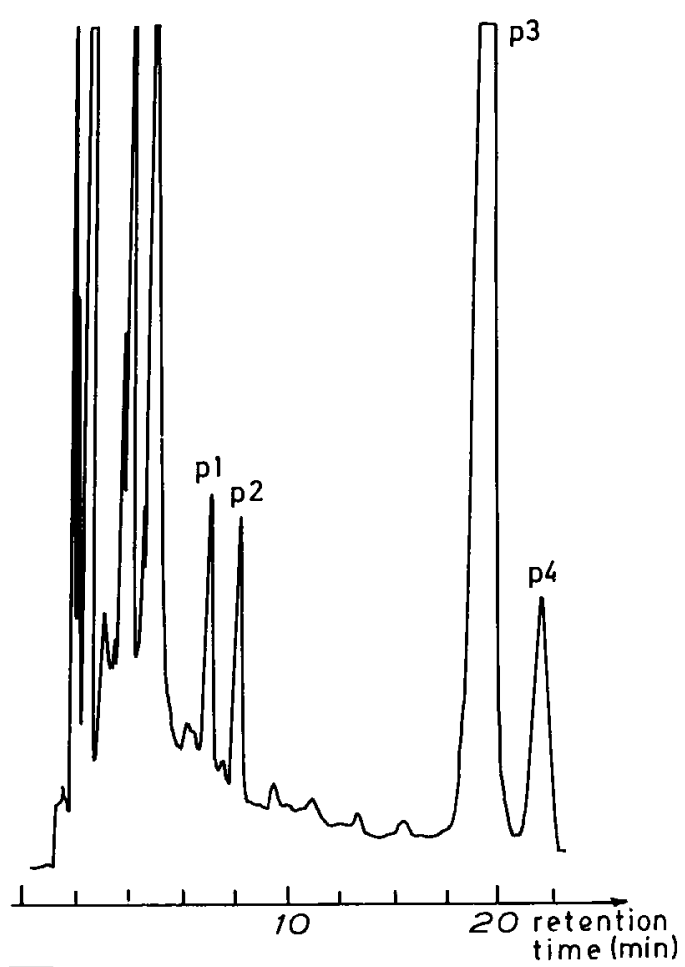

Fig 1. Chromatogram from a fritted-glass bubbler sample. The concentration of 1,6-hexamethylene diisocyanate (p 1) corresponds to $0.53 \mu \mathrm{g} / \mathrm{ml}$.

Table 1. Recoveries of 1,6-hexamethylene diisocyanate (HDI) in the laboratory chemosorption experiments.

\begin{tabular}{lccc}
\hline $\begin{array}{l}\text { Amount of } \\
\text { HDI added } \\
(\mu \mathrm{g})\end{array}$ & $\begin{array}{c}\text { Recovery } \\
(\%)\end{array}$ & $\begin{array}{c}\text { Relative } \\
\text { standard } \\
\text { deviation } \\
(\%)\end{array}$ & $\begin{array}{c}\text { Number of } \\
\text { experiments }\end{array}$ \\
\hline 0.105 & 91 & 14 & 6 \\
1.05 & 90 & 6 & 6 \\
5.25 & 81 & 8 & 6
\end{tabular}

Stored for one week in the dark at room temperature $\begin{array}{llll}1.05 & 83 & 5 & 4\end{array}$ 
higher amount of HDI, $5.25 \mu \mathrm{g}$, were connected to a backup chemosorption tube. No HDI derivative could be detected in any of the backup tubes. The amount of HDI added corresponded to $0.007,0.07$ and $0.35 \mathrm{mg} / \mathrm{m}^{3}$, respectively, for a $15-1$ air sample. Exposed chemosorption tubes can be stored for at least one week in the dark, with a slight decrease in recovery. It has previously been demonstrated (1) that unexposed chemosorption tubes are stable for at least two weeks if stored in the dark at room temperature.

\section{Field studies}

The amount of HDI derivative found in the fritted-glass bubbler solution was used as reference in the experiments and set at 1.00. The amount of HDI varied between 0.34 and $1.10 \mu \mathrm{g}$ when 3.5 to 221 of air, corresponding to air concentrations of $0.014-0.139 \mathrm{mg} / \mathrm{m}^{3}$, was sampled. As can be seen from tables 2 and 3 , there was excellent agreement in collection efficiency between the two sampling methods used for the 3.5- to 22-min sampling periods. However extension of the sampling period to $37-60 \mathrm{~min}$ resulted in considerably lower amounts of the HDI derivative in the fritted-glass bubblers (0.7-1.6 $\mu \mathrm{g})$ compared with the chemosorption tubes $(1.9-2.4 \mu \mathrm{g})$. No HDI could be detected in any of the fritted-glass bubblers used as backups.

Compared with the chromatograms from the chemosorption tubes (fig 2), the chromatograms from the fritted-glass bubblers contained several additional peaks (fig 1). To determine whether these peaks were related to the HDI content,

Table 2. Field sampling of 1,6-hexamethylene diisocyanate (HDI) with chemosorption tubes and frittedglass bubbler samplers containing the reagent 9 -(N-methylaminomethyl) anthracene.

\begin{tabular}{|c|c|c|c|c|}
\hline $\begin{array}{l}\text { Sample } \\
\text { number }\end{array}$ & $\begin{array}{l}\text { Sampling } \\
\text { period } \\
\text { (min) }\end{array}$ & $\begin{array}{c}\text { Effective } \\
\text { paint spraying } \\
(m \neq n)\end{array}$ & $\begin{array}{l}\text { Amount of } \mathrm{HDI} \\
\text { in chemosorption } \\
\text { tubes }\left(\mathrm{mg} / \mathrm{m}^{3}\right)\end{array}$ & $\begin{array}{c}\text { Amount of } \mathrm{HDI} \text { in } \\
\text { fritted-glass } \\
\text { bubbler }\left(\mathrm{mg} / \mathrm{m}^{3}\right)\end{array}$ \\
\hline 1 & 7.7 & 5 & 0.139 & 0.136 \\
\hline 2 & 7.7 & 5 & 0.130 & 0.136 \\
\hline 3 & 7.7 & 5 & 0.143 & 0.143 \\
\hline 4 & 20.0 & 6 & 0.015 & 0.019 \\
\hline 5 & 20.0 & 6 & 0.014 & 0.017 \\
\hline 6 & 22.0 & 4 & 0.035 & 0.037 \\
\hline 7 & 22.0 & 4 & 0.035 & 0.034 \\
\hline 8 & 22.0 & 4 & 0.033 & 0.035 \\
\hline 9 & 36.9 & 6 & 0.054 & 0.019 \\
\hline 10 & 36.9 & 6 & 0.058 & 0.025 \\
\hline 11 & 36.9 & 6 & 0.049 & 0.035 \\
\hline 12 & 60.0 & 10 & 0.042 & 0.018 \\
\hline 13 & 60.0 & 10 & 0.038 & 0.013 \\
\hline 14 & 60.0 & 10 & 0.039 & 0.027 \\
\hline 15 & 11.5 & 3 & 0.048 & 0.040 \\
\hline 16 & 11.5 & 3 & 0.035 & 0.042 \\
\hline 17 & 11.5 & 3 & 0.030 & 0.031 \\
\hline 18 & 19.0 & 7 & 0.058 & 0.056 \\
\hline 19 & 19.0 & 7 & 0.048 & 0.053 \\
\hline 20 & 19.0 & 7 & 0.053 & 0.042 \\
\hline 21 & 7.0 & 4 & 0.106 & 0.104 \\
\hline 22 & 7.0 & 4 & 0.094 & 0.106 \\
\hline 23 & 7.0 & 4 & 0.080 & 0.080 \\
\hline
\end{tabular}

Table 3. Collection efficiency of chemosorption tubes, compared with that of the fritted-glass bubbler, in field studies at two different factories.

\begin{tabular}{lcccc}
\hline $\begin{array}{l}\text { Sampling } \\
\text { technique }\end{array}$ & $\begin{array}{c}\text { Sampling } \\
\text { period } \\
\text { (min) }\end{array}$ & $\begin{array}{c}\text { Relative } \\
\text { recovery }\end{array}$ & $\begin{array}{c}\text { Relative } \\
\text { standard } \\
\text { deviation (\%) }\end{array}$ & $\begin{array}{c}\text { Number of } \\
\text { experiments }\end{array}$ \\
\hline Bubbler & $3.5-22$ & 1.00 & -14 & 17 \\
Chemosorption & $3.5-22$ & 0.96 & -17 & 6 \\
Bubbler & $37-60$ & 1.00 & 25 & 6 \\
Chemosorption & $37-60$ & 2.30 & 6 \\
\hline
\end{tabular}


we used a generalized pattern recognition technique. Using all peak heights simultaneously, this method recognizes similarities and dissimilarities in the pattern of peaks from each sample. With the chemometrical method PLS $(12,22)$ it is possible to recognize correlation patterns in a training set of data; these patterns are then used to predict properties in a test set. In the present case we wished to investigate correlations between the HDI peak height and the additional peaks (p2-p4). In a first step of statistical treatment, all the samples were used in a training set to see if different groupings of samples appeared. In a second step, the samples from factory A were compared with the samples from factory B.

The first PLS analysis resulted in a twodimensional model. The plot, fig 3 , can be seen as a two-dimensional projection of the three dimensional space spanned by the peaks $\mathrm{p} 2-\mathrm{p} 4$. Two classes of data emerged - one group including samples 1-8 from factory $A$ and $15-23$ from factory $B$, and a smaller group containing samples 9-14 from factory A.

In a second analysis, samples $1-8$ from factory A were used as a training set, and samples 15-23 from factory B were used as a test set. The model built on the training set (sample 1-8) explained $93 \%$ of the variance in the HDI peak height. With the use of the factory A model, amounts of HDI in the test set sample (numbers 1523) were predicted from the $\mathrm{p} 2-\mathrm{p} 4$ peaks. The mean value of the predicted amounts of HDI was $116 \%$ of the estimated value, with a relative standard deviation of 18 . In other words the pattern of peaks in the chromatograms from the two industries was similar, and the three additional peaks were closely related to the amount of HDI. Each of the peak heights p2-p4 showed a linear relationship to $\mathrm{p} 1$.

Then a separate model was set up for samples 9-14. Seventy percent of the variance in $\mathrm{p} 1$ could be explained by this model. This model is not quite as good as the first, but it does show that the samples are similar within this group. In samples 9-14,37-60 1 of air was sampled in comparison with 5-22 1 for the rest of the samples. On the assumption that $\mathrm{p} 2-\mathrm{p} 4$ are derivatives of isocyanate with the same detector response as for the pl peak, the total amount of iso-

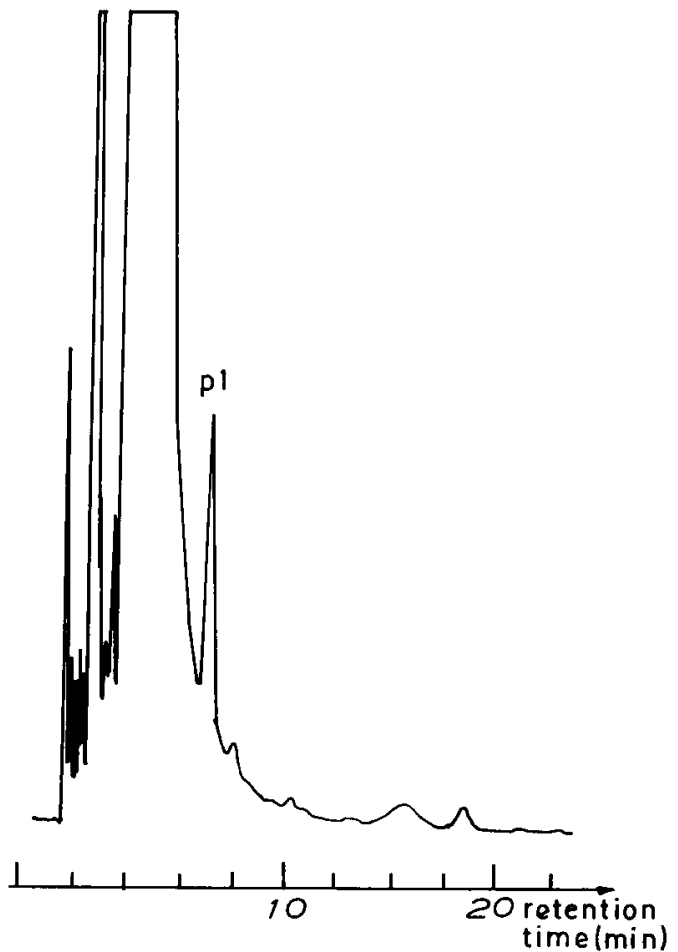

Fig 2. Chromatogram from a chemosorption tube sample. The concentration of 1,6-hexamethylene diisocyanate ( $p$ 1) corresponds to $0.55 \mu \mathrm{g} / \mathrm{ml}$.

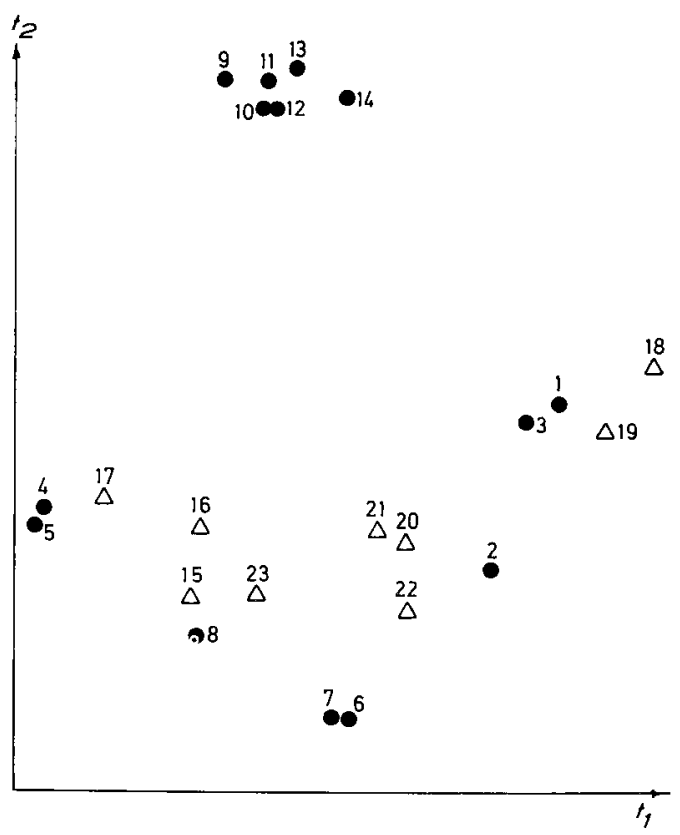

Fig 3. Principal component scores $\left(t_{1}\right.$ and $\left.t_{2}\right)$ for samples 1 to 23. [For a detailed explanation of this type of plot, see Wold et al (22).] 
cyanates can be calculated. In samples 9-14 the total amount was 4-6 $\mu \mathrm{g}$ compared to 3-12 $\mu \mathrm{g}$ in samples $1-8$ and 15-23. Thus the difference in the patterns of the two classes cannot be explained by an insufficient amount of MAMA reagent.

Large air-sampling volumes change the pattern of $\mathrm{p} 1-\mathrm{p} 4$ in the chromatograms. This phenomenon may be caused by loss of substance from the fritted-glass bubbler solutions due, for example, to degradation of substance or breakthrough in the fritted-glass bubbler solutions.

\section{Conclusion}

Chemosorption is a convenient method for sampling HDI. The chemosorption tubes are easy to prepare, are stable enough to be stored before and after use, and HDI is effectively retained on the chemosorption tubes. The sampling is efficient even for large amounts of sampled air, and no complication is caused by additional peaks in the chromatograms. A fritted-glass bubbler containing MAMLA reagent should not be used for sampling larger volumes of air than $20 \mathrm{l}$, since the collection efficiency of such a sampler decreases with increased sampling volume.

It is of the utmost importance to verify the additional peaks in the HPLC chromatograms from the solvent sampler. These peaks are suspected to be derivatives of polymeric HDI. If this should prove to be the case, the question should be considered whether these substances are respirable and whether it is relevant to measure them.

\section{Acknowledgments}

Our thanks are due to Ms M Lutti, Gävle Labour Inspectorate, for arranging for the field sampling of HDI. We also wish to thank S Hellberg, BSc, Department of Organic Chemistry, University of Umeå, for his assistance and for valuable discussions on the statistical treatment of the data.

\section{References}

1. Andersson K, Gudéhn A, Levin JO, Nilsson CA. Analysis of gaseous diisocyanates in air using chemosorption sampling. Chemosphere 11 (1982) 3-10.

2. Andersson K, Gudéhn A, Levin JO, Nilsson CA. A comparative study of solvent and solvent-free sampling methods for airborne 4,4'-diphenylmethane diisocyanate (MDI) generated in polyurethane production. Am ind hyg assoc $\mathrm{j}$ (in press).

3. Chang SN, Burg WR. Determination of airborne 2,4-toluene-diisocyanate vapours. J chromatogr 246 (1982) 113-120.

4. Dunlap KL, Sandridge RL, Keller J. Determination of isocyanates in working atmospheres by high speed liquid chromatography. Anal chem 48 (1976) 497-499.

5. Eicken $\mathrm{S}$ von. Die Bestimmung von Desmodur $\mathrm{H}$ (Hexamethylendiisocyanat) in Luft. Michrochim acta (1958) 731-735.

6. Esposito GG, Dolzine TW. Determination of 1,6-hexamethylene diisocyanate by gas chromatography. Anal chem 54 (1982) $1572-1575$.

7. Goldberg PA, Walker RF, Ellwood PA, Hardy HL. Determination of trace atmospheric isocyanate concentrations by reversed-phase high-performance liquid chromatography using 1-(2-pyridyl)piperazine reagent. $\mathrm{J}$ chromatogr 212 (1981) 93-104.

8. Graham JD. Simplified sample handling procedure for monitoring industrial isocyanates in air. $\mathrm{J}$ chromatogr sci 18 (1980) 384-387.

9. Keller J, Dunlap KL, Sandridge RL. Determination of isocyanates in the working atmospheres by thin-layer chromatography. Anal chem 46 (1974) 1845-1846.

10. Kormos LH, Sandridge RL, Keller J. Determination of isocyanates in air by liquid chromatography with fluorescence detection. Anal chem 53 (1981) 1122-1125.

11. Levine SP, Hogatt JH, Chladek E, Jungclaus G, Gerlock JL. Determination of aliphatic isocyanates in air by a liquid chromatographic-fluorescence technique. Anal chem 51 (1979) 1106-1109.

12. Lindberg W, Persson J $\AA$, Wold S. Partial least squares method for spectrofluorometric analysis of mixtures of humic acid and ligninsulfonate. Anal chem 55 (1983) 643-648.

13. National Institute for Occupational Safety and Health. NIOSH information profiles on potential occupational hazards. US Department of Commerce, National Technical Information Service, Rockville, MD 1977. (PB-276 678, O 1977).

14. National Institute for Occupational Safety and Health. NIOSH criteria for a recommended standard: Occupational exposure to diisocyanates. US Department of Health, Education and Welfare, Public Health Service, Center for Disease Control, Cincinnati, OH 1978. (PB-78 215, S 1978).

15. National Institute for Occupational Safety 
and Health. 4,4-Methylenebis(phenyl isocyanate) (MDI). In: National Institute for Occupational Safety and Health. NIOSH manual of analytical methods. Volume 7. Cincinnati OH, 1981. (method no P \& cam $347,1-13,1981$ ).

16. Pilz W, Johann I. Spezielle analytische Methoden für die Arbeitsmedizin und Industriehygiene: IV Die Bestimmung von Mikrogrammengen Hexamethylendiisocyanat (Desmodur $\mathrm{H}$ ) in Luft sowie wässrigen Hexamethylendiaminlösungen im $0.01 \mathrm{ppm}$ Bereich. Michrochim acta (1970) 351-358.

17. Sangö C. Improved method for determination of traces of isocyanates in working atmospheres by high performance liquid chromatography. J liq chromatogr 2 (1979) $763-774$

18. Sangö C, Zimerson E. A new reagent for determination of isocyanates in working atmospheres by HPLC using UV or fluorescence detection. $\mathrm{J}$ liq chromatogr 3 (1980) 971-990.

19. Tucker SP, Arnold JE. Sampling and determination of 2,4-bis(carbonylamino)toluene and 4,4'-bis-(carbonylamino)diphenylmethane in air. Anal chem 54 (1982) 1137-1141.

20. Walker RF, Pinches MA. Spectrophotometric determination of aliphatic isocyanates in the occupational atmosphere. Analyst 104 (1979) 928-936.

21. Warwick CJ, Bagon DA, Purnell CJ. Application of electrochemical detection to the measurements of free monomeric aromatic and aliphatic isocyanates in air by high performance liquid chromatography. Analyst 106 (1981) 676-685.

22. Wold S, Albano C, Dunn WJ, Esbensen K, Hellberg S, Johansson E, Sjöström M. Pattern recognition: Finding and using regularities in multivariate data. In: Martens H, Russwurm $\mathrm{H}$, ed. Food research and data analysis. Applied Science Publishers, London 1983.

Received for publication: 1 June 1983 